\title{
Influence of Composition and Thermal Treatments on the Martensitic Transition of Cu-Al-Mn Alloys
}

\author{
E. Obradó, L. Mañosa and A. Planes \\ Departament d'Estructura i Constituents de la Matèria, Facultat de Física, Universitat de Barcelona, \\ Diagonal 647, 08028 Barcelona, Catalonia, Spain
}

\begin{abstract}
We have studied the martensitic transformation and the order-disorder transitions in two families of composition related $\mathrm{Cu}-\mathrm{Al}-\mathrm{Mn}$ crystals. X-ray diffraction and calorimetric measurements have been performed to characterize order-disorder transitions. The entropy change at the martensitic transition has been computed from calorimetric measurements. Results show that its magnitude depends only on the martensite structure which, in turn, depends on the electronic concentration e/a. We have obtained $\Delta S=1.51 \pm 0.05 \mathrm{~J} \mathrm{~mol}^{-1} \mathrm{~K}^{-1}$ for a transition to a $2 \mathrm{H}$ phase and $\Delta S=1.26 \pm 0.06 \mathrm{~J} \mathrm{~mol}^{-1} \mathrm{~K}^{-1}$ for a transition to a $18 \mathrm{R}$ structure. We discuss the possibility of a magnetic contribution to $\Delta S$. Finally it is found that quenching has a marked influence on the martensitic transition temperature, but it does not affect the entropy change.
\end{abstract}

\section{INTRODUCTION}

The stability of the bcc phase exhibited at high temperature by numerous metals and alloys stems from the excess of vibrational entropy of this phase in relation to the close-packed structures that would be the stable phases from purely energetic considerations [1]. At low temperature, when the entropic term in the free energy is compensated by the energetic one, most of these systems undergo a martensitic transition to a close-packed structure [2]. Among the different systems undergoing a martensitic transition, a technologically interesting family is the one formed by Cu-based alloys. They belong to the Hume-Rothery class of materials for which the phase stability is dominated by the average number of valence electrons per atom ratio (e/a) [3]. In this family, commonly the bcc phase is only stable at high temperature but it can be retained at low temperature by means of a suitable cooling. For certain compositions this metastable bcc phase undergoes a martensitic transition. In addition, during cooling, these systems get configurationally ordered, and the degree of order achieved by the samples depends on the cooling rate; this is an important result since ordering can modify the relative stability between bcc and martensitic phases [4].

In this work we study the $\mathrm{Cu}-\mathrm{Al}-\mathrm{Mn}$ alloy system. In many respects, this alloy behaves very similarly to standard $\mathrm{Cu}$-based alloys like $\mathrm{Cu}-\mathrm{Zn}-\mathrm{Al}$ or $\mathrm{Cu}-\mathrm{Al}-\mathrm{Ni}$, but a significant difference is that $\mathrm{Cu}-\mathrm{Al}-\mathrm{Mn}$ is paramagnetic while other $\mathrm{Cu}$-based alloys are diamagnetic. Hence, short range magnetic order could have an influence on the phase stability of $\mathrm{Cu}-\mathrm{Al}-\mathrm{Mn}$. We have first characterized the (metastable) phase diagram and we have measured entropy changes during martensitic transition in two families of composition related $\mathrm{Cu}-\mathrm{Al}-\mathrm{Mn}$ crystals. Finally we have also analyzed the influence of quenches from above and below the ordering temperatures on the martensitic transition. 
Table 1: Composition, e/a, martensitic transition temperature $\left(\mathrm{M}_{s}\right)$, latent heat (on cooling, $\mathrm{L}_{c}$, and on heating, $L_{h}$ ) and entropy change $(\Delta S)$ of the different alloys investigated. The first set of alloys belongs to the $\mathrm{Cu}_{3} \mathrm{Al}-\mathrm{Mn}$ line and the second one to the $\mathrm{Cu}_{3} \mathrm{Al}-\mathrm{Cu}_{3} \mathrm{Mn}_{2}$ line.

\begin{tabular}{|c|cc|c|c|cc|c|}
\hline Alloy & at.\% Al & at.\% Mn & e/a & $\mathbf{M}_{s}(\mathrm{~K})$ & $\mathbf{L}_{c}(\mathrm{~J} / \mathrm{mol})$ & $\mathbf{L}_{h}(\mathrm{~J} / \mathrm{mol})$ & $\Delta \mathbf{S}(\mathrm{J} / \mathrm{mol} \mathrm{K})$ \\
\hline $\mathrm{Cu}_{3} \mathrm{Al}$ & 24.7 & 0.0 & 1.494 & 600 & - & - & - \\
$\mathrm{A} 1$ & 24.9 & 5.0 & 1.499 & 281 & 391 & 410 & 1.46 \\
$\mathrm{~A} 2$ & 23.6 & 6.3 & 1.472 & 251 & 356 & 404 & 1.55 \\
$\mathrm{~A} 3$ & 23.8 & 6.9 & 1.475 & 218 & 329 & 354 & 1.53 \\
$\mathrm{~A} 4$ & 22.9 & 7.9 & 1.458 & 180 & 235 & 266 & 1.37 \\
$\mathrm{~A} 5$ & 22.8 & 9.0 & 1.456 & 133 & 140 & 175 & 1.24 \\
\hline $\mathrm{B} 00$ & 21.9 & 5.3 & 1.437 & - & - & - & - \\
$\mathrm{B} 05$ & 21.5 & 6.2 & 1.430 & 383 & - & - & - \\
$\mathrm{B} 1$ & 21.7 & 7.0 & 1.435 & 355 & 435 & 436 & 1.24 \\
$\mathrm{~B} 15$ & 20.3 & 8.2 & 1.405 & 350 & - & - & - \\
$\mathrm{B} 2$ & 20.0 & 9.1 & 1.399 & 294 & 368 & 396 & 1.32 \\
$\mathrm{~B} 3$ & 18.7 & 10.8 & 1.375 & 181 & 201 & 219 & 1.20 \\
\hline
\end{tabular}

\section{EXPERIMENTAL}

Samples belonging to the two composition related alloy families, $\left(\mathrm{Cu}_{0.75} \mathrm{Al}_{0.25}\right)_{1-x} \mathrm{Mn}_{x}(0 \leq \mathrm{x} \leq 0.09)$ and $\mathrm{Cu}_{3} \mathrm{Al}_{1-x} \mathrm{Mn}_{2 x}(0 \leq \mathrm{x} \leq 0.22)$, have been used in the experiments. Their specific compositions are given in table 1 . Polycrystalline cylindrical shaped ingots $(5 \mathrm{~mm}$ diameter) were obtained by melting pure elements (purity 99.99\%). From them, slices ( $2 \mathrm{~mm}$ thick) have been cut using a low speed diamond saw. The damaged surface has been etched away in a $40 \% \mathrm{HNO}_{3}$ solution.

Calorimetric measurements between $100 \mathrm{~K}$ and room temperature have been performed using a microcalorimeter specifically designed to investigate solid-solid phase transitions (details of this instrument can be found in [5]). A differential scanning calorimeter from TA Instruments has been used for the range $300-850 \mathrm{~K}$ and, for temperatures above $850 \mathrm{~K}$, phase transitions have been detected using a high temperature differential thermal analysis cell. In all cases, the studied sample has been first heat treated for $900 \mathrm{~s}$ at $1080 \mathrm{~K}$, air cooled to a temperature $\mathrm{T}_{q}$ and quenched in a mixture of ice and water. The reference heat treatment consisted of a direct quench from $1080 \mathrm{~K}$ followed by a three-day room temperature ageing.

\section{RESULTS}

\subsection{Phase Diagram}

In this section we present the (metastable) phase diagram corresponding to the two studied composition lines. Results have been obtained with samples that have followed a reference heat treatment. The order-disorder transitions have been characterized by means of x-ray diffraction and calorimetric measurements. Except in $\mathrm{Cu}_{3} \mathrm{Al}$, all studied samples display two order-disorder transitions at high temperature and a martensitic transition at a lower temperature. $\mathrm{In} \mathrm{Cu}-\mathrm{Al}-\mathrm{Mn}$ samples, it has been found that the order-disorder transitions are continuous from $\mathrm{A} 2$ to $\mathrm{B} 2$ and $\mathrm{B} 2$ to $\mathrm{L} 22_{1}$ structures. In fig. 1 we present typical $x$-ray results together with the recorded thermogram. In contrast with these results, $\mathrm{Cu}_{3} \mathrm{Al}$ undergoes a unique order-disorder transition from a disordered (A2) to a $\mathrm{DO}_{3}$ ordered structure.

The metastable phase diagrams for the two studied composition lines, showing the ordering tem- 


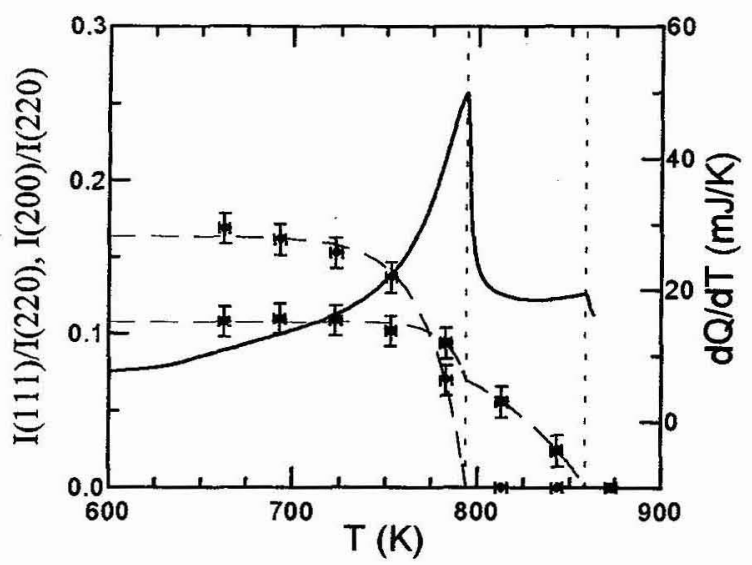

Figure 1: Relative integrated intensities of the x-ray (111) L2 superstructure peak $(\bullet)$ and (200) B2 superstructure peak ( $\mathbf{m}$ ) obtained on heating powders of the A4 alloy, and thermogram recorded on heating a sample of the same composition. Dotted lines are guides to the eye.

peratures and martensitic $\mathrm{M}_{s}$ temperatures as a function of $\mathrm{Mn}$ concentration are given in fig. 2a and $2 \mathrm{~b}$.

Regarding the martensitic transition, it is worth noting that the martensitic structure depends on $\mathrm{e} / \mathrm{a}$. The resulting structure has been identified by means of $\mathrm{x}$-ray diffraction and it has been found that for $\mathrm{e} / \mathrm{a} \leq 1.46$ the martensitic structure is $18 \mathrm{R}$ while for $\mathrm{e} / \mathrm{a} \geq 1.46$ it is $2 \mathrm{H}$ [6]. The e/a values of the studied alloys have been calculated from their composition assuming that each $\mathrm{Cu}$ atom contributes with 1 electron, each $\mathrm{Al}$ atom, with 3 and each $\mathrm{Mn}$ atom, with 1 [7]. It is remarkable that we have detected the change from the $18 \mathrm{R}$ to the $2 \mathrm{H}$ martensite at an e/a value quite coincident with the e/a value at which the two phase boundaries of the high temperature bcc stability region in the equilibrium phase diagram [8] meet each other (eutectoid point).
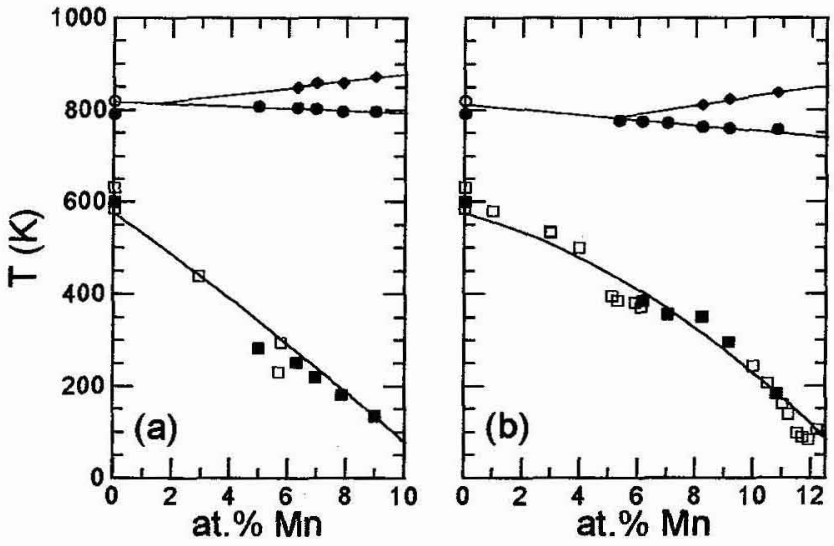

Figure 2: Metastable phase diagram of (a) the $\mathrm{Cu}_{3} \mathrm{Al}-\mathrm{Mn}$ line, and (b) the $\mathrm{Cu}_{3} \mathrm{Al}-\mathrm{Cu}_{3} \mathrm{Mn}_{2}$ line. 4 : B2-A2 transition temperatures. •: L2 $2_{1}-\mathrm{B} 2$ transition temperatures. $=\mathrm{M}_{s}$ temperatures. Solid symbols: present measurements. Open symbols: values taken from the literature. Lines are fits to the experimental data. 


\subsection{Martensitic Transition}

The entropy $(\Delta S)$ and the enthalpy (latent heat, $L$ ) changes at the martensitic transition have been obtained from calorimetric measurements after a proper correction of the calorimetric baseline as described in [9]. Within experimental uncertainties (evaluated to be less than 5\%) no systematic differences between the $\Delta S$ values for forward (cooling) and reverse (heating) transitions have been detected. Therefore, we have computed the entropy difference between $\beta$ and martensitic phases as an average of these two absolute values [6].

Since the martensitic structure depends on e/a, $\Delta S$ is likely to depend also on this parameter. In fig. 3 we have plotted $\Delta \mathrm{S}$ as a function of e/a for all the investigated samples. The data exhibit a jump from a constant value $\Delta \mathrm{S}=1.26 \pm 0.06 \mathrm{~J} / \mathrm{K} \mathrm{mol}$ for $\mathrm{e} / \mathrm{a}<1.46$ up to a constant value $\Delta \mathrm{S}=1.51 \pm 0.05 \mathrm{~J} / \mathrm{K} \mathrm{mol}$ for $\mathrm{e} / \mathrm{a}>1.46$. Such a discontinuity occurs at an $\mathrm{e} / \mathrm{a}$ value coincident with

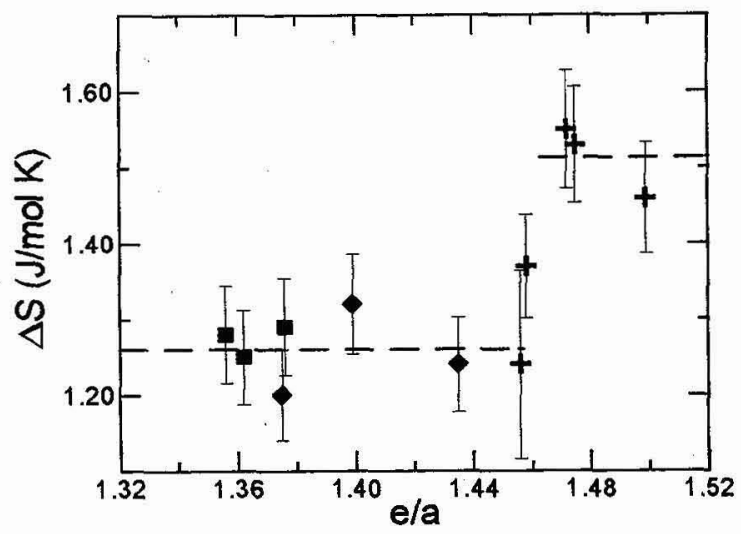

Figure 3: Entropy change at the martensitic transition in $\mathrm{Cu}-\mathrm{Al}-\mathrm{Mn}$, from present experiments $\left(+: \mathrm{Cu}_{3} \mathrm{Al}-\right.$ Mn line, $\bullet \mathrm{Cu}_{3} \mathrm{Al}-\mathrm{Cu}_{3} \mathrm{Mn}_{2}$ line) and from M.O. Prado, P.M. Decorte and F. Lovey, Scripta Metall. Mater. 33, 877 (1995) (-). Horizontal lines: average values for $\mathrm{e} / \mathrm{a} \leq 1.45$ (18R martensite) and for $\mathrm{e} / \mathrm{a} \geq 1.47$ (2H martensite).

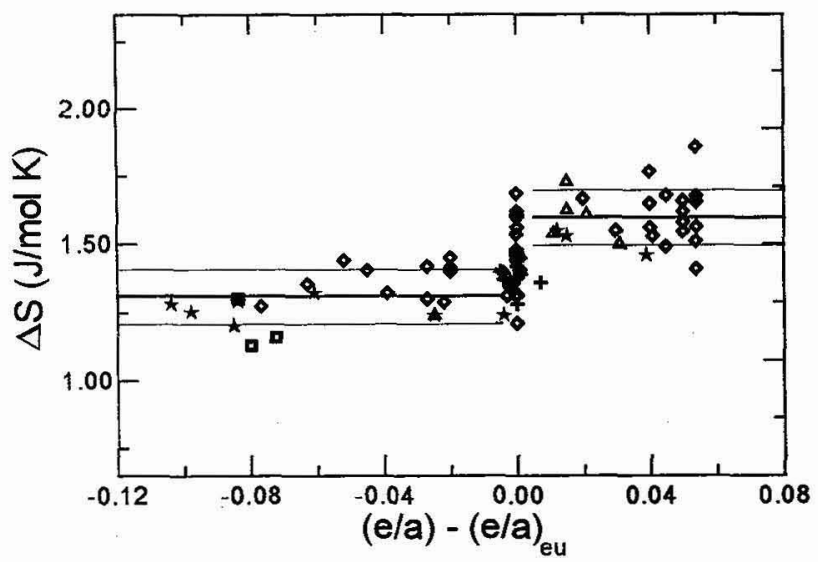

Figure 4: Entropy changes for $\mathrm{Cu}-\mathrm{Zn}-\mathrm{Al}(\diamond), \mathrm{Cu}-\mathrm{Zn}(\square), \mathrm{Cu}-\mathrm{Al}-\mathrm{Ni}(\triangle), \mathrm{Cu}-\mathrm{Al}-\mathrm{Be}(+)$ and $\mathrm{Cu}-\mathrm{Al}-\mathrm{Mn}(*)$, as a function of $\alpha \equiv \mathrm{e} / \mathrm{a}-(\mathrm{e} / \mathrm{a})_{e u}$. Data are collected from a large number of papers, and include present results for $\mathrm{Cu}-\mathrm{Al}-\mathrm{Mn}$. Continuous lines are averages for $\alpha \leq-0.01$ and $\alpha \cdot \geq 0.01$, and dashed lines indicate in each case the corresponding standard deviation. 
that where the martensitic structure has been reported to change from $18 \mathrm{R}$ to $2 \mathrm{H}$ and, as previously mentioned, this is very close to the eutectoid point of the equilibrium phase diagram. In order to check whether this result can be extended to other $\mathrm{Cu}$-based alloys, we have collected a large number of data from the literature for different $\mathrm{Cu}$-based systems. These data are plotted (including present values for $\mathrm{Cu}-\mathrm{Al}-\mathrm{Mn})$ in fig. 4 as a function of $\alpha \equiv \mathrm{e} / \mathrm{a}-(\mathrm{e} / \mathrm{a})_{e u}$, where $(\mathrm{e} / \mathrm{a})_{e u}$ corresponds to the eutectoid point. It is clear from the figure that $\Delta \mathrm{S}$ values collapse onto a single step function that changes from $1.31 \pm 0.10 \mathrm{~J} / \mathrm{K} \mathrm{mol}$ to $1.60 \pm 0.10 \mathrm{~J} / \mathrm{K}$ mol at $\alpha=0$. Present results render an entropy difference of $\sim 0.3 \mathrm{~J} / \mathrm{K} \mathrm{mol}$ between the $2 \mathrm{H}$ and $18 \mathrm{R}$ martensitic phases, independent of the alloy system. This value is in good agreement with the values reported from stress-strain measurements [10-12].

The fact that $\Delta \mathrm{S}$ values for $\mathrm{Cu}-\mathrm{Al}-\mathrm{Mn}$ coincide (within the experimental errors) with those for other $\mathrm{Cu}$-based nonmagnetic alloys, enables us to establish that a possible magnetic contribution to the whole measured entropy change should be very small. Hence, we conclude that for $\mathrm{Cu}$-based alloys, the entropy excess of the $\beta$ phase mostly stems from the vibrational degrees of freedom.

The enthalpy changes computed at the forward (cooling) and reverse (heating) martensitic transitions are shown in table 1. Their composition dependence shows a behavior similar to the one exhibited by the martensitic transition temperature. This is due to the fact that there are no significant differences among the entropy changes of the different samples. As is usual, the enthalpy change value obtained at the reverse transition is higher than that obtained at the forward transition, since the reverse transformation occurs at a higher temperature [9].

\subsection{Quenching effects}

The effect of quenches from different temperatures $\mathrm{T}_{q}$ up to $1080 \mathrm{~K}$ has been investigated in an $\mathrm{A} 2$ sample. In order to quantify the change in the transition temperature with $\mathrm{T}_{q}$, we have plotted in fig. 5 the temperature where the relative amount of martensite formed in the sample is 0.5 [13], $\mathrm{T}_{0.5}$, as a function of the quenching temperature $\mathrm{T}_{q}$. There is a marked decrease in $\mathrm{T}_{0.5}$. on increasing $\mathrm{T}_{q}$. The entropy change $\Delta \mathrm{S}$ is, within the experimental error, independent of $\mathrm{T}_{q} . \mathrm{A}$ decrease of the martensitic transition temperature with $\mathrm{T}_{q}$ has also been reported for $\mathrm{Cu}-\mathrm{Zn}$ - $\mathrm{Al}$ [14], while an increase is observed for $\mathrm{Cu}-\mathrm{Al}-\mathrm{Be}$ [15]. However, in the case of $\mathrm{Cu}-\mathrm{Al}-\mathrm{Mn}$ the dependence of $\mathrm{T}_{0.5}$ with $\mathrm{T}_{q}$ is monotonous in the whole temperature range investigated, and the extrema observed for $\mathrm{Cu}-$ $\mathrm{Zn}-\mathrm{Al}$ and $\mathrm{Cu}-\mathrm{Al}-\mathrm{Be}$ around the order-disorder transition temperature have not been detected here.

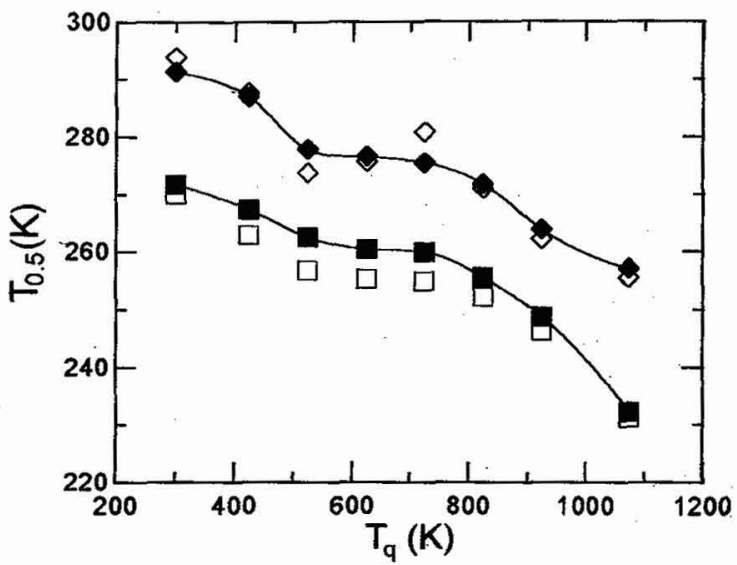

Figure 5: Martensitic transition temperature dependence on the quenching temperature for the A2 $\mathrm{Cu}$ Al-Mn alloy.m: forward transition; $\star$ reverse transition. Open symbols: measured immediately after the quench. Solid symbols: after a 23 -hour ageing at room temperature ( $\beta$ phase). 
This seems to be an indication that the mechanism which modifies the martensitic transition temperature in $\mathrm{Cu}-\mathrm{Al}-\mathrm{Mn}$ is different from the mechanism in other $\mathrm{Cu}$-based alloys.

\section{CONCLUDING REMARKS}

The metastable phase diagram of $\beta$-Cu-Al-Mn has been obtained. Two continuous order-disorder transitions, from $\mathrm{A} 2$ to $\mathrm{B} 2$ and from $\mathrm{B} 2$ to $\mathrm{L} 21_{1}$ structures, have been detected. A martensitic transition occurs to a $2 \mathrm{H}$ structure for an e/a value higher than that of the eutectoid point and to a $18 \mathrm{R}$ structure for $\mathrm{e} / \mathrm{a}$ less than this value. This is the general behavior for $\mathrm{Cu}$-based shape-memory alloys.

The entropy and enthalpy changes at the martensitic transition have been measured. It has been found that the entropy change is a constant value that depends on the martensitic structure formed, and that there is an entropy difference of $0.3 \mathrm{~J} / \mathrm{K} \mathrm{mol}$ between the $2 \mathrm{H}$ and the $18 \mathrm{R}$ phases. It has been shown that these entropy change values are the same for all Cu-based shape-memory alloys. Then, it has been established that there is no significant magnetic contribution to this entropy change in $\mathrm{Cu}-\mathrm{Al}-\mathrm{Mn}$.

Finally, the effect of quenches from different temperatures over the martensitic transition has been studied. Though they do not affect the transition entropy change, it has been observed that increasing the quench temperatures reduces considerably the martensitic transition temperature. It has been shown that this behavior is different from the one obtained in other $\mathrm{Cu}$-based alloys.

\section{Acknowledgments}

Samples were kindly provided by M. Morin, INSA, Lyon (France). This work has received financial support from the CICyT (Spain), project MAT95-0504 and from the CIRIT (Catalonia), project SGR119. E.O. acknowledges financial support from DGICyT (Spain).

\section{References}

[1] W. Petry, J. de Phys. IV 5, C2-15 (1995).

[2] L. Delaey, Materials Science and Technology, Vol. 5: Phase Transformations in Materials, edited by P. Haasen (VCH, Weinheim, 1991), p.339.

[3] T.B. Massalski and U. Mizutani, Prog. Mater. Sci. 22, 151 (1978).

[4] J. Elgueta, J.L. Macqueron and A. Planes, J. Phys. Condens. Matter 4, 285 (1992).

[5] G. Guénin et al., Proc. ICOMAT'86. The Japan Institute of Metals, Nara 1986, p. 794.

[6] E. Obradó, L1. Mañosa and A. Planes, Phys. Rev. B 56, 20 (1997).

[7] B. Caroli and A. Blandin, J. Chem. Phys. Solids 27, 503 (1967).

[8] J.M. Scarabello, Ph.D. Thesis, Université Claude-Bernard, Lyon, 1984.

[9] J. Ortín and A. Planes, Acta Metall. 36, 1873 (1988).

[10] H. Kato and S. Miura, Acta Metall. Mater. 43, 351 (1995).

[11] J. Ortín, Ll. Mañosa, C.M. Friend, A. Planes and M. Yoshikawa, Philos. Mag. A 65, 461 (1992).

[12] K. Otsuka, C.M. Wayman, K. Nakai, H. Sakamoto and K. Shimitzu, Acta Metall. 24, 207 (1976).

[13] The relative amount of martensite formed (as a function of temperature) is computed when the entropy and enthalpy changes are obtained. See ref. [9] for details.

[14] A. Planes, J.L. Macqueron, R. Rapacioli and G. Guénin, Philos. Mag. A 61, 221 (1990).

[15] M. Jurado, Ll. Mañosa and A. Planes, Phys. Rev. B 48, 3540 (1993). 